\title{
Água purificada para laboratório: qualidade microbiológica, formação de biofilme e uso do ozônio como sanificante alternativo
}

\author{
Patrícia Lunardelli Negreiros de CARVALHO ${ }^{1 *}$ \\ Samir Antonio Rodrigues ABJAUDE ${ }^{2}$ \\ Taciane Maira Magalhães HIPOLITO ${ }^{3}$ \\ Antônio dos Reis LOPES ${ }^{4}$ \\ Luiz Carlos do NASCIMENTO 5 \\ Sandra Maria Oliveira Morais VEIGA ${ }^{6}$
}

\author{
${ }^{1}$ Mestre em Ciências Farmacêuticas. Universidade Federal de Alfenas (UNIFAL-MG). E-mail: patrikapnc@gmail.com \\ ${ }^{2}$ Farmacêutico. UNIFAL-MG. E-mail: samirabjaude@hotmail.com \\ ${ }^{3}$ Mestranda em Ciências Farmacêuticas. UNIFAL-MG. E-mail: taciane.unifal@gmail.com \\ ${ }^{4}$ Farmacêutico. UNIFAL-MG. E-mail: tonpharma@gmail.com \\ ${ }^{3}$ Doutor, Professor de Microbiologia de Alimentos e Saúde Coletiva. UNIFAL-MG E-mail: \\ luizcnascimento@gmail.com \\ ${ }^{4}$ Doutora, Professora de Saúde Coletiva aplicada à Farmácia, Controle de Qualidade Microbiológica de Alimentos e \\ Microbiologia de Alimentos. UNIFAL-MG. E-mail: smveiga@gmail.com
}

Recebido em: 29/10/2012 - Aprovado em: 28/12/2012 - Disponibilizado em: 30/12/2012

\author{
*AUTOR CORRESPONDENTE: Patrícia Lunardelli Negreiros de Carvalho \\ Endereço: Universidade Federal de Alfenas, UNIFAL-MG, Campus Alfenas, Rua Gabriel Monteiro da Silva, 700 , \\ 37130-000, Alfenas-MG, Brasil \\ Tel: (35)3299-1465 \\ E-mail: patrikapnc@gmail.com
}

Resumo: A purificação da água utilizada em laboratórios e estabelecimentos de saúde é realizada por diferentes métodos, dependendo da sua finalidade. A presença de micro-organismos é permitida na mesma, desde que estejam dentro de limites especificados na legislação vigente e não sejam patogênicos. Assim, este trabalho avaliou a qualidade da água proveniente de equipamentos purificadores (destiladores e deionizadores), quanto aos agentes formadores de biofilmes. Também foram examinados fatores interferentes (mangueira, resina e água de abastecimento do equipamento) e a ação sanificante do ozônio sobre os micro-organismos isolados. Investigaram-se Pseudomonas, aeróbios mesófilos (AM) e fungos filamentosos e leveduras (FFL). Constatou-se que todas as amostras de água de deionizadores apresentaram quantificação de AM fora dos padrões recomendados. Adicionalmente, $60 \%$ das amostras apresentaram FFL e Pseudomonas aeruginosa. Apenas uma amostra de água destilada (estocada por mais de 24h) evidenciou valores de $\mathrm{AM}>10 \mathrm{UFC} / \mathrm{mL}$ bem como $P$. aeruginosa. Nas resinas detectaram-se AM $\left(\mathrm{m}=1,75 \times 10^{2} \mathrm{UFC} / \mathrm{cm}^{2}\right), \quad P$. aeruginosa $\left(\mathrm{m}=2,03 \times 10^{2} \mathrm{UFC} / 100 \mathrm{~cm}^{2}\right)$ e FFL $\left(\mathrm{m}=2,5 \times 10^{1} \mathrm{UFC} / \mathrm{cm}^{2}\right)$. Encontraram-se quantidades elevadas de AM $\left(\mathrm{m}=7,0 \times 10^{1} \mathrm{UFC} / \mathrm{cm}^{2}\right)$, FFL $\quad\left(\mathrm{m}=2,5 \times 10^{3} \mathrm{UFC} / \mathrm{cm}^{2}\right)$ e $P$. aeruginosa $\left(\mathrm{m}=1,0 \times 10^{3} \mathrm{UFC} / 100 \mathrm{~cm}^{2}\right)$ em $66,67 \%$ das mangueiras dos destiladores. Verificou-se contaminação da água após o processo de purificação (passagem pela resina), principalmente nos deionizadores, uma vez que a análise da qualidade da água que os abastecia estava dentro do permitido pela legislação vigente. Quanto aos micro-organismos isolados, o ozônio foi capaz de diminuir 9 ciclos log em 5 segundos. Portanto, o uso de água purificada e ozonizada se torna uma opção interessante e prática como sanificante alternativo.

Palavras-chave: Biofilme. Destilador. Deionizador. Qualidade da Água. Ozônio.

\section{Purified water laboratory: microbiological quality, biofilm formation and use of ozone as alternative sanitizer}

\begin{abstract}
The purification of water used in laboratories and healthcare facilities should be performed by different methods, depending on your purpose. The presence of micro-organisms is allowed on the same, provided they are within the limits specified in legislation and are not pathogenic. Thus, this study evaluated the quality of water from scrubbers equipment (distillators and deionizeds) agents forming biofilms. Also examined were interfering factors (hose, resin and water supply equipment) and sanitizing ozone action on micro-organisms isolated. Pseudomonas were investigated, mesophilics aerobics (AM) and filamentous fungi and yeasts (FFY). It was found that all water samples showed deionizeds quantification AM outside the recommended standards. Additionally, $60 \%$ of the samples had FYF and Pseudomonas aeruginosa. Only one sample of distilled water (stored for more than 24 hours) showed values of AM $>10 \mathrm{CFU} / \mathrm{ml}$, and $P$. aeruginosa. Resins were detected AM $\left(\mathrm{m}=1,75 \times 10^{2} \mathrm{CFU} / \mathrm{cm}^{2}\right)$, P. aeruginosa $\left(\mathrm{m}=2,03 \times 10^{2} \mathrm{CFU} / 100 \mathrm{~cm}^{2}\right)$ and FFY $\left(\mathrm{m}=2,5 \times 10^{1} \mathrm{CFU} / \mathrm{cm}^{2}\right)$. We found high amounts of AM $\left(\mathrm{m}=7,0 \times 10^{1} \mathrm{CFU} / \mathrm{cm}^{2}\right)$, FFY $\left(\mathrm{m}=2,5 \times 10^{3} \mathrm{CFU} / \mathrm{cm}^{2}\right)$ and $P$. aeruginosa $\left(\mathrm{m}=1,0 \times 10^{3} \mathrm{CFU} / 100 \mathrm{~cm}^{2}\right)$ in $66,67 \%$ of the hoses from the distillators.
\end{abstract}


There was water contamination after the purification process (passing through resin), mainly in deionizeds, since the analysis of water quality that was supplied to the extent permitted by law. As for the micro-organisms isolated, ozone was able to decrease 9 cycles log in 5 seconds. Therefore, the use of ozonated and purified water becomes an attractive option as sanitizing and practical alternative.

Keywords: Biofilm. Distillator. Deionized. Water Quality. Ozone.

\section{INTRODUÇÃO}

Devido ao amplo uso da água em laboratórios farmacêuticos, cosméticos e de alimentos, seja no preparo de fórmulas farmacêuticas e cosméticas ou, ainda, nas diversas etapas de higienização e operações unitárias destes ambientes, a água merece especial atenção (BOTET, 2006; SILVA et al., 2005).

A água pode receber tratamento diferenciado de purificação, conforme a aplicação que se deseja, sendo os métodos de destilação e deionização mais rotineiramente empregados (MACEDO, 2007). O monitoramento constante da qualidade microbiológica é exigido por lei para os estabelecimentos de saúde, indústria farmacêutica, laboratórios e farmácias (BRASIL, 2010a).

Dentre as legislações da ANVISA que regulamentam a produção ou manipulação de medicamentos, tem-se a Resolução RDC $\mathrm{n}^{\mathrm{o}}$ 17/2010 (BRASIL, 2010b), que trata das Boas Práticas de Fabricação para Indústria Farmacêutica, e a Resolução RDC $\mathrm{n}^{\circ}$ 214/2006 (BRASIL, 2006), que estabelece as

Boas Práticas de Manipulação de Medicamentos para uso Humano em Farmácias. Ambas são importantes, pois indicam que a água para fins farmacêuticos deve ser adequadamente purificada para o uso ao qual se destina.

A água potável servida no Brasil pela rede pública também deve obedecer à Portaria do Ministério da Saúde MS no . 2.914, de 12 de dezembro de 2011, a qual estabelece a Norma de Qualidade da Água Para Consumo Humano e dispõe sobre os procedimentos de controle e de vigilância da qualidade da água, bem como seu padrão de potabilidade (BRASIL, 2011).

Deste modo, a qualidade físico-química e microbiológica da água (purificada ou potável) deve ser constantemente avaliada e os processos que permitem a eliminação de micro-organismos patogênicos e deteriorantes da água adquirem, cada vez mais, importância sanitária, econômica e social (PADRÓN et al., 1986; GERMANO; GERMANO, 2000).

De acordo com Macedo (2007), algumas contaminações microbiológicas da água estão associadas à presença de biofilmes aderidos nas superfícies das tubulações, filtros, conexões e tanques de estocagem. No biofilme, os micro-organismos estão mais resistentes à ação de agentes químicos e físicos, como aqueles usados em procedimentos de higienização (PARIZZI, 1998; MOSTELLER; BISHOP, 1993). Esse acúmulo indesejável de depósitos biológicos sobre uma superfície contribui com a 
diminuição da eficiência e da vida útil do equipamento.

Desta forma, o procedimento de higienização dos equipamentos purificadores de água deve ser periódico, para evitar a formação de biofilme bacteriano nas paredes do reservatório, equipamentos, conexões, entre outros (MACEDO, 2007).

Considerando o exposto, este trabalho avaliou a qualidade da água proveniente de equipamentos purificadores (destiladores e deionizadores), quanto aos agentes formadores de biofilmes, além de examinar fatores interferentes (mangueira, resina e água de abastecimento do equipamento) e a ação sanificante do ozônio sobre os microorganismos isolados.

\section{MATERIAIS E MÉTODOS}

Foram analisadas, em duplicata, 11 amostras de água oriundas de purificadores, sendo 06 destiladores (A-DEST) e 05 deionizadores (A-DEIO), além de 04 amostras de resinas provenientes destes deionizadores e 03 amostras de mangueiras dos destiladores analisados previamente (a conexão que sai do filtro de água e chega ao destilador). Complementarmente, analisaramse também 07 amostras de água de abastecimento dos equipamentos, cuja resina e mangueiras foram avaliadas.
Análise microbiológica das amostras de água purificada e da rede de abastecimento

Procedeu-se a coleta das amostras de água dos destiladores ou deionizadores monitorados, bem como da água da rede de abastecimento destes equipamentos, de forma asséptica, utilizando frascos estéreis, com capacidade para $200 \mathrm{~mL}$ de amostra. Ressalva-se que nas coletas de água de abastecimento foram utilizados frascos contendo tiossulfato de sódio, para neutralizar o cloro residual. Após a coleta, as amostras foram devidamente identificadas, acondicionadas em caixa isotérmica e direcionadas para a realização das análises físico-químicas e ensaios microbiológicos.

Pesquisaram-se micro-organismos formadores de biofilmes (Pseudomonas aeruginosa), empregando a técnica da membrana filtrante descrita em Silva et al. (2005), filtrando-se $100 \mathrm{~mL}$ de água e, posteriormente, acoplando-se a membrana ao ágar Cetrimide. As placas foram incubadas em estufa $35-37^{\circ} \mathrm{C} / 24 \mathrm{~h}$ e, em seguida, realizou-se a contagem das colônias típicas, procedendo às provas bioquímicas descritas por Bier (1978).

Realizou-se também a avaliação microbiológica das amostras de água, por meio da contagem de aeróbios mesófilos (AM - técnica do pour plate) e fungos filamentosos e leveduras (FFL-técnica da semeadura) (SILVA et al., 2005; SILVA et al., 2007; APHA, 2005). Para completar os resultados 
microbiológicos, determinou-se também o $\mathrm{pH}$ das amostras de água analisadas.

Os dados obtidos foram comparados aos instrumentos legais vigentes: Portaria $n^{\circ}$ 2.914/2011 (água de abastecimento), RDC $\mathrm{n}^{\circ}$ 67/2007 e Farmacopéia Brasileira (BRASIL, 2010a), ambas para água purificada.

\section{Análise microbiológica das mangueiras e resinas}

Utilizou-se a técnica do "swab", friccionando-o em uma área de $50 \mathrm{~cm}^{2}$. Posteriormente, fez-se uma suspensão do material em $50 \mathrm{~mL}$ de solução salina estéril com $10 \%$ de tween 80 , de forma que cada $\mathrm{mL}$ da suspensão correspondesse ao material amostrado em uma área correspondente a um $\mathrm{cm}^{2}$. Em seguida, procederam-se os ensaios microbiológicos para contagem de Pseudomonas aeruginosa (utilizou-se $10 \mathrm{~mL}$ da suspensão obtida, adicionada de $90 \mathrm{~mL}$ de salina e posterior filtração em membrana) e quantificação de Aeróbios Mesófilos e fungos filamentosos e leveduras. O resultado foi expresso em UFC/mL da suspensão ou $\mathrm{UFC} / \mathrm{cm}^{2}$ da superfície analisada.

\section{Metodologia para avaliação da eficiência} do ozônio, como sanificante alternativo.

\section{-Obtenção das suspensões microbianas}

Foram preparadas suspensões com $5 \mathrm{~mL}$ de salina estéril, a partir das cepas de $P$. aeruginosa isoladas, em fase logarítmica, utilizando-se o tubo número 4 da escala de McFarland como padrão comparativo.
Alíquotas de 0,5 mL de cada tubo foram transferidas para um único tubo, formando um pool das dez cepas isoladas durante o estudo. Deste pool, considerado como controle, fez-se plaqueamento para a contagem do número de bactérias.

\section{-Produção da salina ozonizada}

Para a produção de salina ozonizada, foram adicionados $99 \mathrm{~mL}$ de salina estéril a um reator de cristal, com capacidade para 100 $\mathrm{mL}$, vedado com Parafilm ${ }^{\circledR}$ (para evitar a degasagem). Com auxílio de um difusor de bolhas finas, borbulhou-se a mistura ozônio/oxigênio, produzida por gerador de ozônio (Ozonic®, com capacidade de produção de $2 \mathrm{~g} / \mathrm{h}$, quando acoplado ao cilindro de oxigênio).

\section{-Experimento}

$\mathrm{O}$ experimento foi conduzido em duplicata, utilizando-se um tratamento com ozônio e quatro tempos de avaliação, de acordo com a metodologia de Veiga et al. (2003), com algumas modificações.

Ao colocar o volume de $99 \mathrm{~mL}$ de salina estéril no reator de cristal, o sistema de ozonização foi acionado por 20 minutos, para obter a saturação de, aproximadamente, 1,2 $\mathrm{mg} / \mathrm{L}$.

Em seguida, adicionou-se ao reator, 1 $\mathrm{mL}$ da suspensão de bactérias (pool) a ser tratada. O tempo foi cronometrado e mantevese o fluxo de ozônio constante, até a finalização do experimento. 
Coletaram-se alíquotas de $1 \mathrm{~mL}$ nos tempos $05,15,30$ e 60 segundos, as quais foram rapidamente transferidas para tubos contendo $10 \mu \mathrm{L}$ de tiossulfato de sódio, a $2 \%$, com a finalidade de neutralizar o ozônio remanescente. Posteriormente, $0,1 \mathrm{~mL}$ das amostras coletadas, nos tempos prédeterminados, bem como suas diluições, foram inoculadas, em duplicata, em meio de cultura apropriado (Ágar Cetrimide) e incubadas a $37^{\circ} \mathrm{C} / 24 \mathrm{~h}$.

\section{-Titulação}

A concentração de ozônio foi avaliada pelo método iodimétrico, titulando-se a água ozonizada produzida no reator de cristal (MAGNAGO et al., 2005; APHA, 2005).

\section{RESULTADOS E DISCUSSÕES}

\section{-Análise das amostras de água purificada}

A Farmacopéia Brasileira (BRASIL, 2010a) especifica que a água purificada deve estar com ausência de Pseudomonas em 100 $\mathrm{mL}$ de água e a contagem de bactérias total não deve ultrapassar $100 \mathrm{UFC/mL}$.

Na Tabela 1, estão dispostos os valores de $\mathrm{pH}$ e os resultados das análises microbiológicas (quantificação de Aeróbios Mesófilos (AM, UFC/mL), P. aeruginosa (UFC/100mL) e Fungos Filamentosos e Leveduras (FFL, UFC/mL) das amostras de água provenientes dos destiladores (DEST) e deionizadores (DEIO) analisados.

De acordo com os parâmetros aceitos pela RDC no 67/2007, apenas uma amostra
(20\%) de A-DEIO apresentou o valor de $\mathrm{pH}$ fora do limite permitido $(6,0-9,5)$ (Tabela 1$)$. Neste parâmetro, as amostras de A-DEST apresentaram-se dentro dos valores aceitos.

Os resultados microbiológicos evidenciaram elevada contaminação da ADEIO em relação a A-DEST (Tabela 1).

A presença de $P$. aeruginosa foi observada em $60 \%$ das amostras de A-DEIO e em 16,67\% de A-DEST, referente a uma amostra dentre as seis analisadas, sendo esta a única cujo estoque no barrilete ultrapassou 24 horas, reforçando a sugestão apresentada pela Farmacopéia Brasileira (BRASIL, 2010a) de que o estoque de água destilada por tempo maior que este, influencia negativamente a qualidade microbiológica da água, tornando-a inapropriada para o uso farmacêutico.

Em relação à quantificação de AM, $100 \%$ das amostras de A-DEIO apresentaramse em desconformidade com os padrões recomendados. Ao contrário, apenas a amostra de A-DEST estocada por mais de $24 \mathrm{~h}$ evidenciou valores maiores que $10 \mathrm{UFC} / \mathrm{mL}$ (510 UFC/mL), reforçando o discutido anteriormente. Deve-se assinalar que, para as águas deionizadas e destiladas, o nível de alerta em relação aos AM é da ordem de $10^{2}$ UFC/mL (BRASIL, 2010a).

Com relação aos FFL nos deionizadores, 60\% das amostras de água analisadas apresentaram valores iguais ou maiores que $10^{3} \mathrm{UFC} / \mathrm{mL}$. Ressalta-se que o valor de $\mathrm{pH}$ baixo $(5,5)$ possivelmente 
contribuiu com o maior desenvolvimento de

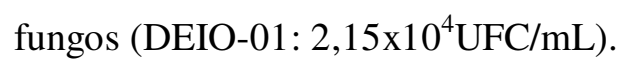

Em relação à análise microbiológica da água para fins farmacêuticos, Bara et al. (2005) verificaram que, dentre as 59 amostras analisadas, $44 \%$ estavam em desacordo com as especificações farmacopeicas; entre as amostras reprovadas, detectaram-se problemas em duas amostras de água destilada e 24 amostras de água deionizada, cujos valores da contagem padrão de bactérias heterotróficas variaram de 1,2 a 2,3 x $10^{3}$ UFC/g. Os autores também concordam que a qualidade microbiológica da água deionizada constitui um problema a ser solucionado. Aconselharam que a saturação da resina do deionizador, a manutenção inadequada do equipamento e da caixa d'água podem maximizar os problemas detectados.

Tabela 1 - Resultados das análises microbiológicas e valores de $\mathrm{pH}$ das amostras de água provenientes de destiladores (DEST) e deionizadores (DEIO).

\begin{tabular}{ccccc}
\hline Equipamento & $\mathbf{p H}$ & $\begin{array}{c}\text { AM } \\
(\mathbf{U F C} / \mathbf{m L})\end{array}$ & $\begin{array}{c}\boldsymbol{P} \text {. aeruginosa } \\
\text { (UFC/100mL) }\end{array}$ & $\begin{array}{c}\text { FFL } \\
\text { (UFC/mL) }\end{array}$ \\
\hline DEST-01 & 6,0 & $1,0 \times 10^{1}$ & Ausência & Ausência \\
DEST-02 & 7,0 & Ausência & Ausência & Ausência \\
DEST-03 & 7,0 & 5,0 & Ausência & $1,0 \times 10^{2}$ \\
DEST-04 & 7,0 & 3,0 & Ausência & Ausência \\
DEST-05 & 6,5 & $1,0 \times 10^{1}$ & Ausência & Ausência \\
DEST-06 & 6,5 & $5,1 \times 10^{2}$ & $5,0 \times 10^{2}$ & $1,0 \times 10^{2}$ \\
DEIO-01 & 5,5 & $1,44 \times 10^{3}$ & $1,35 \times 10^{2}$ & $2,15 \times 10^{4}$ \\
DEIO-02 & 7,0 & $1,07 \times 10^{4}$ & Ausência & $5,38 \times 10^{3}$ \\
DEIO-03 & 7,0 & $8,05 \times 10^{4}$ & Ausência & $4,73 \times 10^{3}$ \\
DEIO-04 & 7,0 & $3,20 \times 10^{2}$ & $7,5 \times 10^{2}$ & Ausência \\
DEIO-05 & 7,0 & $1,0 \times 10^{4}$ & $3,9 \times 10^{1}$ & Ausência \\
\hline
\end{tabular}

Fonte: os autores

-Análise das amostras de resina e mangueira

As análises microbiológicas da mangueira, assim como da resina, se tornam importantes para demonstrar que a qualidade da água purificada proveniente do equipamento está exclusivamente relacionada com o processo de purificação, bem como, com a manutenção e higienização que este equipamento recebe periodicamente. Assim, é possível comparar a eficiência de purificação entre os destiladores e deionizadores.
Nas resinas analisadas (Tabela 2), detectaram-se AM, Pseudomonas e FFL. Verificou-se, assim, a importância de fatores, como a vida útil da resina, sua recuperação e possível sanificação da água obtida, pois o deionizador não produz água purificada com baixos níveis de micro-organismos nem é capaz de eliminá-los.

Ainda nesta Tabela 2 é possível reforçar a importância da limpeza e troca periódica das mangueiras que comunicam o filtro de água com o equipamento destilador de água. 
Verificou-se que $66,67 \%$ das mangueiras apresentaram-se com elevadas contagens de AM e FFL. Além disso, duas amostras analisadas foram positivas para $P$. aeruginosa, bactéria potencialmente formadora de biofilme.

De acordo com Pinto; Kaneko; Ohara (2000), independente do processo utilizado, o desenvolvimento de biofilmes pode ocorrer, de acordo com a qualidade da água de alimentação e do regime de operação do sistema de tratamento.

Comparando os resultados na Tabela 3 , verificou-se ocorrência de contaminação da água posteriormente ao processo de purificação. É possível observar que o caso se agrava, principalmente após a passagem pela resina.

Tabela 2 - Resultado das análises microbiológicas realizadas para a resina dos deionizadores (R-DEIO) e para mangueiras que saem do filtro e chegam ao destilador (MG-DEST).

\begin{tabular}{cccc}
\hline Equipamento & $\begin{array}{c}\text { AM } \\
\left(\mathbf{U F C} / \mathbf{c m}^{\mathbf{2}}\right)\end{array}$ & $\begin{array}{c}\boldsymbol{P} \text { a aeruginosa } \\
\left(\mathbf{U F C} / \mathbf{1 0 0 \mathbf { c m } ^ { 2 }}\right)\end{array}$ & $\begin{array}{c}\text { FFL } \\
(\mathbf{U F C} / \mathbf{c m})^{\mathbf{2}}\end{array}$ \\
\hline R-DEIO-01 & Ausência & $36 \times 10^{1}$ & Ausência \\
R-DEIO-02 & $2,0 \times 10^{2}$ & $4,0 \times 10^{1}$ & Ausência \\
R-DEIO-03 & $1,0 \times 10^{2}$ & Ausência & $1,0 \times 10$ \\
R-DEIO-04 & $4,0 \times 10^{2}$ & 5,0 & $9,0 \times 10$ \\
\hline MG-DEST-04 & $1,9 \times 10^{3}$ & $>1,0 \times 10^{3}$ & $2,5 \times 10^{3}$ \\
MG-DEST-05 & $2,0 \times 10^{2}$ & Ausência & $5,0 \times 10^{3}$ \\
MG-DEST-06 & 1,0 & $>1,0 \times 10^{3}$ & Ausência \\
\hline
\end{tabular}

Fonte: os autores

Tabela 3 - Compilação dos resultados de equipamentos com dados microbiológicos e pH do monitoramento das amostras de água de abastecimento (AA), resina (R) ou mangueira (MG) e água purificada proveniente de deionizador (DEIO) e destilador (DEST)

\begin{tabular}{|c|c|c|c|c|}
\hline ORIGEM & $\begin{array}{c}\mathrm{AM} \\
\left(\mathrm{UFC} / \mathrm{mL} \text { ou } \mathrm{cm}^{2}\right)\end{array}$ & $\begin{array}{c}\text { FFL } \\
\left(\mathrm{UFC} / \mathrm{mL} \text { ou } \mathrm{cm}^{2}\right)\end{array}$ & $\begin{array}{c}P \text {. aeruginosa } \\
\left(\mathrm{UFC} / 100 \mathrm{~mL} \text { ou } 100 \mathrm{~cm}^{2}\right)\end{array}$ & pH \\
\hline AA-DEIO-01 & 4,0 & $3,0 \times 10^{2}$ & Ausência & 7,0 \\
\hline R-DEIO-01 & 0 & 0 & Presente & - \\
\hline DEIO-01 & $1,44 \times 10^{3}$ & $2,15 \times 10^{4}$ & Presente & 5,5 \\
\hline AA-DEIO-02 & $2,0 \times 10^{1}$ & 5,0 & Ausência & 7,0 \\
\hline R-DEIO-02 & $2,0 \times 10^{1}$ & 0 & Presente & - \\
\hline DEIO-02 & $1,07 \times 10^{4}$ & $5,383 \times 10^{3}$ & Ausência & 7,0 \\
\hline AA-DEIO-03 & 1,50 & $1,65 \times 10^{3}$ & Ausência & 7,0 \\
\hline R-DEIO-03 & $1,0 \times 10^{1}$ & 1,0 & Ausência & - \\
\hline DEIO-03 & $8,05 \times 10^{4}$ & $4,73 \times 10^{3}$ & Ausência & 7,0 \\
\hline AA-DEIO-04 & $4,25 \times 10^{2}$ & $9,0 \times 10^{2}$ & Ausência & 6,5 \\
\hline R-DEIO-04 & $4,0 \times 10^{1}$ & 9,0 & Presente & - \\
\hline DEIO-04 & $3,2 \times 10^{2}$ & 0 & Presente & 7,0 \\
\hline AA-DEST-04 & $1,08 \times 10^{2}$ & $1,3 \times 10^{2}$ & Ausência & 7,0 \\
\hline MG-DEST-04 & $1,9 \times 10^{2}$ & $2,5 \times 10^{2}$ & Presente & - \\
\hline DEST-04 & 3,0 & 0 & Ausência & 7,0 \\
\hline AA-DEST-05 & 6,0 & $7,5 \times 10^{1}$ & Ausência & 7,0 \\
\hline MG-DEST-05 & $2,01 \times 10^{2}$ & $5,0 \times 10^{3}$ & Ausência & - \\
\hline DEST-05 & $1,0 \times 10^{1}$ & 0 & Ausência & 6,5 \\
\hline AA-DEST-06 & $3,2 \times 10^{2}$ & $5,0 \times 10^{1}$ & Presente & 7,0 \\
\hline MG-DEST-06 & 1,0 & 0 & Presente & - \\
\hline DEST-06 & $5,1 \times 10^{2}$ & $1,0 \times 10^{2}$ & Presente & 6,5 \\
\hline
\end{tabular}

AM: Aeróbios Mesófilos; FFL: fungos filamentosos e levedura; -: não avaliado. Fonte: os autores. 
-Análise das amostras de água de abastecimento dos equipamentos purificadores

A água potável, servida no Brasil pela rede pública, deve obedecer à Portaria MS $\mathrm{n}^{\circ}$. 2.914/2011. Assim, fez-se análise microbiológica e determinação do $\mathrm{pH}$, para as amostras de água de abastecimento dos equipamentos, cuja resina e mangueiras foram analisadas (Tabela 3).

$\mathrm{O}$ valor de $\mathrm{pH}$ encontrado para todas as amostras de água de abastecimento dos equipamentos purificadores de água foi adequado.

A contagem de AM observada, apesar de encontrar-se em acordo com o preconizado pela Portaria MS n 2.914/2011, poderia ter apresentado uma redução ainda maior com a limpeza periódica da caixa de água, que contribuiria também com a diminuição nos valores preocupantes encontrados para FFL, tanto na água que abastece destiladores, quanto deionizadores.

Destaca-se também a presença de $P$. aeruginosa na amostra AA-DEST-06.

Comparando estes resultados (Tabela 3) aos da Tabela 1, reforça-se a possibilidade da ocorrência de contaminação posterior ao processo de purificação (após passagem pela resina), principalmente nos deionizadores.

Tabela 4 - Avaliação da eficiência da água ozonizada sobre as cepas de Pseudomonas detectadas neste estudo

\begin{tabular}{ccccc}
\hline Contagem inicial & $\mathbf{t}=\mathbf{5} \mathbf{s}$ & $\mathbf{t}=\mathbf{1 5}$ & $\mathbf{t}=\mathbf{3 0 s}$ & $\mathbf{t}=\mathbf{6 0 s}$ \\
\hline $2,64 \times 10^{15} \mathrm{UFC} / \mathrm{mL}$ & $5,0 \times 10^{6} \mathrm{UFC} / \mathrm{mL}$ & $5,0 \times 10^{6} \mathrm{UFC} / \mathrm{mL}$ & $9,25 \times 10^{4} \mathrm{UFC} / \mathrm{mL}$ & $4,25 \times 10^{4} \mathrm{UFC} / \mathrm{mL}$ \\
\hline
\end{tabular}

Fonte: os autores

-Eficiência do ozônio sobre as cepas de $P$. aeruginosa isoladas

Após a realização da titulação e dos cálculos para a dosagem de ozônio em água, verificou-se que a concentração de ozônio obtida no experimento foi de 1,2 ppm.

Os resultados, em $\quad \mathrm{UFC} / \mathrm{mL}$, alcançados no experimento estão expostos na Tabela 4.

Verificou-se que houve redução de 9 ciclos log após 5 e 15 segundos de ozonização; e, redução de 11 ciclos log após 30 e 60 segundos de tratamento. Assim, a redução foi de $100 \%$, estando o ozônio apto para ser utilizado como sanificante alternativo, após a obtenção de água purificada.

$\mathrm{Na}$ literatura, Veiga et al. (2003) também observaram a eficiência do ozônio sobre cepas de $P$. aeruginosa (ATCC 27853), e verificaram que o ozônio, na concentração de $0,6 \mathrm{mg} / \mathrm{L}$, foi capaz de reduzir $99,99 \%$, com 5 segundos de exposição.

Os autores Velano et al. (2001) avaliaram, in vitro, a atividade antibacteriana da água ozonizada, frente ao Staphylococcus 
aureus e observaram tempo de 5'25', para a inativação total das bactérias tratadas com água previamente ozonizada $(0,6 \mathrm{mg} / \mathrm{mL})$. Para a água não previamente ozonizada, o tempo foi de 23'45", indicando um efeito antibacteriano mais rápido para a água previamente ozonizada.

Sabe-se que numerosos compostos industriais de desinfecção, além de provocarem mutações, deixam resíduos, enquanto que, no processo de ozonização realizado através de práticas, dosagens e tempo de exposição adequada, não se encontram resíduos e a ação é muito mais eficaz, além de estarem comprovadas as propriedades germicidas do ozônio mediante sua aplicação em diferentes tempos e em determinadas concentrações (BIERNAT et al., 2006; TORRES et al., 1996).

\section{CONCLUSÕES}

Detectaram-se micro-organismos, incluindo $P$. aeruginosa, micro-organismo potencialmente formador de biofilme, nas amostras de água de abastecimento, purificada, mangueiras e resina dos equipamentos amostrados, evidenciando-se a necessidade de monitoramento e higienização periódica do equipamento e acessórios.

O ozônio revelou-se uma alternativa eficaz como tratamento da água purificada, contribuindo com a segurança na utilização desta matéria prima.

\section{AGRADECIMENTOS}

Agradecemos ao apoio financeiro da FAPEMIG.

\section{REFERÊNCIAS BIBLIOGRÁFICAS}

APHA. AMERICAN PUBLIC HEALTH ASSOCIATION. Standard methods for the examination of water and wastewater. 21 th ed. EUA: Editora AWWA, 2005. BARA, M. T. F. et al. Revista Eletrônica de Farmácia, v. 2, n. 2, p. 38-44, 2005.

BIER, O. Bacteriologia e imunologia. 19 ed. São Paulo: Melhoramentos, 1978. 1062p.

BIERNAT, J.C. et al. Amiloidose por hemodiálise: o que pode mudar com ozônio e água ultra-pura?. Medicina avançada, 23 de fevereiro de 2006. Disponível em: $<$ http://www.drashirleydecampos.com.br/noti cias.php?noticiaid $=18684 \&$ assunto $=$ Rim $/$ Rins /Nefrologia $>$. Acesso em: $<12$ de outubro de 2007>.

BOTET, J. Boas práticas em instalações e projetos farmacêuticos. São Paulo: RCN Editora, 2006. 360p.

BRASIL. Farmacopéia Brasileira. $5^{\mathrm{a}}$ ed. Brasília: Agência Nacional de Vigilância Sanitária, 2010a. Volume 1. 546 p.

BRASIL. Ministério da Saúde. Portaria MS $\mathrm{n}^{\mathbf{0}} \mathbf{2 1 9 4}$ de 12 de dezembro de 2011, que dispõe sobre os procedimentos de controle e de vigilância da qualidade da água para consumo humano e seu padrão de potabilidade. Brasília, 2011.

BRASIL. Ministério da Saúde. Resolução RDC no 17 de 16 de Abril de 2010, que dispõe sobre o Regulamento Técnico das Boas Práticas para a Fabricação de Medicamentos. Brasília, 2010b.

BRASIL. Ministério da Saúde. Resolução RDC no 214 de 12 de Dezembro de 2006, que dispõem sobre as Boas Práticas de 
Manipulação de Medicamentos para uso humano em Farmácias. Brasília, 2006.

BRASIL. RDC n⿳ 67 de 08 de Outubro de 2007, que dispõe sobre Boas Práticas de Manipulação de Preparações Magistrais e Oficinais para Uso Humano em Farmácias. Brasília: Ministério da Saúde, 2007.

GERMANO, P. M. L.; GERMANO, M. I. S. A vigilância sanitária de alimentos como fator de promoção da saúde. O Mundo da Saúde, São Paulo, v.24, p.59- 66, jan./fev. 2000.

MACEDO, J. A. B. Águas e águas. 3 ed. Revisada e atualizada. Belo Horizonte: CRQ/MG, 2007. 1043p.

MAGNAGO, L.R.; MARIANO, R.C.; OLIVEIRA, D.I.; FIORINI, J.E.; VEIGA, S. M.O.M. Adequação de um ozonizador doméstico para uso odontológico. In: XI Jornada de Iniciação Científica de Alfenas, 2005, Alfenas. Anais, 2005. v. cd-rom.

MOSTELLER, T.M.; BISHOP, J.R. Sanitizer efficacy against attached bacteria in a milk biofilm. Journal of Food Protection, v. 56, p. 34-41, 1993.

PADRÓN, G. et al. Utilización del ozone como agente desinfectante de aguas contaminadas con Salmonellas. Revista Cubana de Higiene y Epidemiology, v. 24, n. 4, p. 435-438, oct./dic. 1986.

PARIZZI, S.Q.F. Adesão bacteriana em superfície de serviço de alimentação hospitalar avaliada pela microscopia de epifluorescência. 1998. 57p. Dissertação (Mestrado em Ciência e Tecnologia de Alimentos) - Universidade Federal de Viçosa, 1998.

PINTO, T.J.A; KANEKO, T.M.; OHARA, M.T. Controle biológico de qualidade de produtos farmacêuticos, correlatos e cosméticos. São Paulo: Atheneu, 2000. 309 p. de métodos de análise microbiológica de alimentos. 3 ed. São Paulo: Varela, 2007. $552 \mathrm{p}$.

SILVA, N.; NETO, R. C.; JUNQUEIRA, V. C. A.; SILVEIRA, N. F. A. Manual de métodos de análise microbiológica da água. São Paulo: Varela, 2005. 164 p.

TORRES, E. A. F. S.; ROGÊ FERREIRA, A. F.; RÍMOLI, C. D.; OLIVO, R. Estudo das propriedades desinfetantes do ozônio em alimentos. Revista Higiene Alimentar, São Paulo, v. 10, n. 42, p. 18-23, 1996.

VEIGA, S. M. O. M.; NASCIMENTO, L. C.; CARVAlHO, E. P.; CARDOSO, C. C.; FIORINI, J. E. Eficácia da água ozonizada contra patógenos encontrados em água e alimentos. Revista Higiene Alimentar, São Paulo, v. 17, n. 106, p. 95-99, 2003.

VELANO, C.E.E.; NASCIMENTO, L.C.; BARROS, L.M.; PANZERI, H. Avaliação in vitro da atividade antibacteriana da água ozonizada frente ao Staphylococcus aureus. Pesquisa Odontológica Brasileira, v. 15, p. 18-22, 2001.

SILVA, N.; JUNQUEIRA, V. C. A.;

SILVEIRA, N. F. A. TANIWAKI, M.H.;

SANTOS, R.F.S.; GOMES, R.A.R. Manual 